\title{
The Impact of Stigma on People with Opioid Use Disorder, Opioid Treatment, and Policy
}

\author{
Ali Cheetham ${ }^{1,2}$, Louisa Picco', Anthony Barnett ${ }^{1,2}$, Dan I Lubman $\mathbb{D}^{1,2}$, Suzanne Nielsen ${ }^{1,2}$ \\ 'Monash Addiction Research Centre, Eastern Health Clinical School, Monash University Peninsula Campus, Frankston, Victoria, 3199, Australia; \\ ${ }^{2}$ Turning Point, Eastern Health, Richmond, Victoria, 3121 , Australia
}

Correspondence: Suzanne Nielsen, Monash Addiction Research Centre, Eastern Health Clinical School, Monash University Peninsula Campus, 47-49 Moorooduc Hwy, Frankston, Victoria, 3199, Australia, Tel +6I 39904 464I, Email suzanne.nielsen@monash.edu

\begin{abstract}
Illicit drug use disorders are the most stigmatised health conditions worldwide, and stigma acts as a meaningful barrier to treatment entry and treatment provision. In the context of dramatically rising opioid-related harms, it is critical that we understand the drivers of stigma and how it affects opioid use disorder treatment and policy. The aim of this narrative review is to discuss how opioid-related stigma impacts treatment provision and harm reduction, and provide potential strategies to reduce stigma at a social and structural level. We used the Framework for Integrating Normative Influences on Stigma (FINIS) to identify sources of opioid-related stigma at the macro (structural stigma), meso (public stigma) and micro (internalised stigma) levels. Reducing stigma requires strategies that target multiple levels, however addressing inequity in the laws, regulations, and rules that segregate people with opioid and other substance use disorders from mainstream society is essential.
\end{abstract}

Keywords: stigma, opioid use disorder, FINIS, opioid-related disorders, analgesics, Opioid, social stigma

\section{Introduction}

Opioid use disorder is a global health issue, with more than 40 million people estimated to be using opioids in $2017 .{ }^{1}$ Illicit drug use disorders are the most stigmatised health conditions worldwide, and compared to other mental or physical health problems are more likely to be viewed as a personal choice or a sign of weakness or "bad character". ${ }^{2}$ People with opioid use disorders are often perceived as dangerous and unpredictable, subject to high levels of social exclusion, and may be considered unworthy of receiving government assistance with food or housing. ${ }^{3-5}$

However, the ways in which opioid-related stigma is enacted are complex and vary depending on the type of opioid, how it is acquired, and the context of use. As noted by McCradden et al, ${ }^{6}$ an unstable dichotomy exists between "legitimate" use of opioids (ie, medically sanctioned treatment, usually for an objective pathology) and "illegitimate" use (ie, use for recreational purposes or in response to psychological stressors). People who inject illicit opioids tend to be the most stigmatised: although few studies have examined stigma, opioid use, and injecting drug use concurrently, both illicit drug use and intravenous routes of administration are associated with more negative public attitudes and greater barriers to accessing health services. ${ }^{5,7,8}$ Fentanyl use also attracts a high level of stigma, which may be compounded by increased media coverage of overdose deaths with narratives framing the individual as problematic and dangerous (while de-emphasising the responsibilities of health care systems and the pharmaceutical industry). ${ }^{9}$ There is also widespread misinformation among first responders regarding the risks of passive exposure to fentanyl, which may lead to unnecessary precautions that hinder effective overdose response, and entrench beliefs that people who use illicit opioids are dangerous and should be avoided. ${ }^{10,11}$

Substantial increases in opioid prescribing for chronic non-cancer pain over the past 20 years have led to considerable harms, including morbidity and mortality due largely to accidental overdoses. Unlike illicit opioid use and opioid use disorder, media coverage of this issue is less likely to rely on long-standing negative stereotypes about drug users, ${ }^{12,13}$ and people who become addicted to prescription opioids may be conceptualized as having a physical disease rather than being personally responsible for their condition. ${ }^{14}$ Nonetheless, they face high levels of social exclusion, a key indicator 
of behavioural intentions towards stigmatised groups, and may be perceived as incapable of making decisions about finances and treatment. ${ }^{14}$

Experiences in health-care systems that reinforce the moral binary between "good" and "bad" opioid consumption, and "good" and "bad" people who use opioids, can perpetuate stigma among subpopulations of opioid users. For example, chronic non-cancer pain patients report prejudice towards people who are dependent on opioids or use them illicitly. ${ }^{15,16}$ A key way in which patients with chronic pain distance themselves from an "addict" identity is through stigmatising discourse that distinguishes between the "responsible" patient who takes medication for legitimate reasons and those who "chose" to use opioids for pleasure. ${ }^{16}$

It is important to note that the stigma associated with opioid use disorder does not exist in isolation, but intersects with and is compounded by marginalisation linked to race, gender, ethnicity, socioeconomic status, sexual orientation, and age. ${ }^{17,18}$ This is of particular importance in relation to the opioid crisis, which has disproportionally affected communities facing high levels of poverty, income inequality, and lack of access to social capital. ${ }^{19}$ Stigma also creates barriers for people with opioid use disorder in the criminal justice system, with widespread misconceptions regarding the purpose and benefits of treatment leading to programmes that are often unavailable or poorly implemented. ${ }^{20,21}$ Furthermore, the intersection of stigma associated with criminality and substance use can have detrimental impacts on patient self-efficacy and treatment engagement. ${ }^{18}$ There is also some evidence that people with mental health problems who use substances experience differing levels of stigma, ${ }^{17}$ although further research is needed to understand the relationships between specific mental health disorders and opioid or other drug-related stigma.

Although the intersectional nature of opioid-related stigma remains somewhat under-researched, one study identified 8 different forms of stigma among older adult patients receiving methadone, with those reporting greater stigma identifying more barriers to treatment. ${ }^{22}$ Evidence from the broader health literature has highlighted the importance of considering the coexperience of multiple stigmatised identities, as interventions that deal solely with a single health-related stigma are unlikely to have success in reducing social inequality and sustaining improvements in health. ${ }^{23}$ It is therefore critical that we understand the drivers of stigma and how it affects opioid use disorder treatment and policy. The aim of this narrative review is to discuss how opioid-related stigma impacts treatment provision and harm reduction, and provide strategies to reduce stigma at a social and structural level.

\section{Sources of Opioid-Related Stigma}

Stigma is defined by the World Health Organization as 'a mark of shame, disgrace, or disapproval that results in an individual being rejected, discriminated against, and excluded from participating in a number of different areas of society'. ${ }^{24}$ Stigma is a social phenomenon that serves to devalue groups on the basis of particular characteristics, ${ }^{25}$ and comprises three main components arising from problems in knowledge (ignorance/misinformation), attitudes (prejudice), and behaviour (discrimination). These components are interrelated, where a lack of knowledge can result in negative attitudes and prejudice, which then leads to discriminatory behaviour. ${ }^{26}$

Stigma is frequently described as encompassing three interacting types: structural, public and internalised stigma. Structural stigma, also known as institutional stigma, exists at the systems or macro level and is enacted through rules, policies, and practices that constrain the opportunities and resources of the stigmatised group. Public stigma refers to stereotypes and negative attitudes that result in prejudice and discrimination. Self-stigma refers to negative thoughts and feelings that arise from identification with a stigmatised group, and has negative impacts on mental health and wellbeing as well as behaviour (eg, through avoiding treatment, or close contact with others). ${ }^{27}$

Each of these dimensions of stigma serve to reinforce each other, with stigma arising at the inter- and intrapersonal levels whilst being enacted through laws, policies, and regulation. ${ }^{28}$ In this sense, stigma goes beyond those who are stigmatised and is echoed outward through the broader community and inwards through the policies and procedures that guide treatment, including through the staff providing care at health services. ${ }^{29}$ In order to encapsulate these varying types of stigma, Pescosolido et al developed the Framework for Integrating Normative Influences on Stigma (FINIS) which theorises that there are various levels of social life which create normative expectations resulting in the process of stigmatisation. ${ }^{30}$ Using this framework, we have identified sources of opioid-related stigma at the macro (structural 


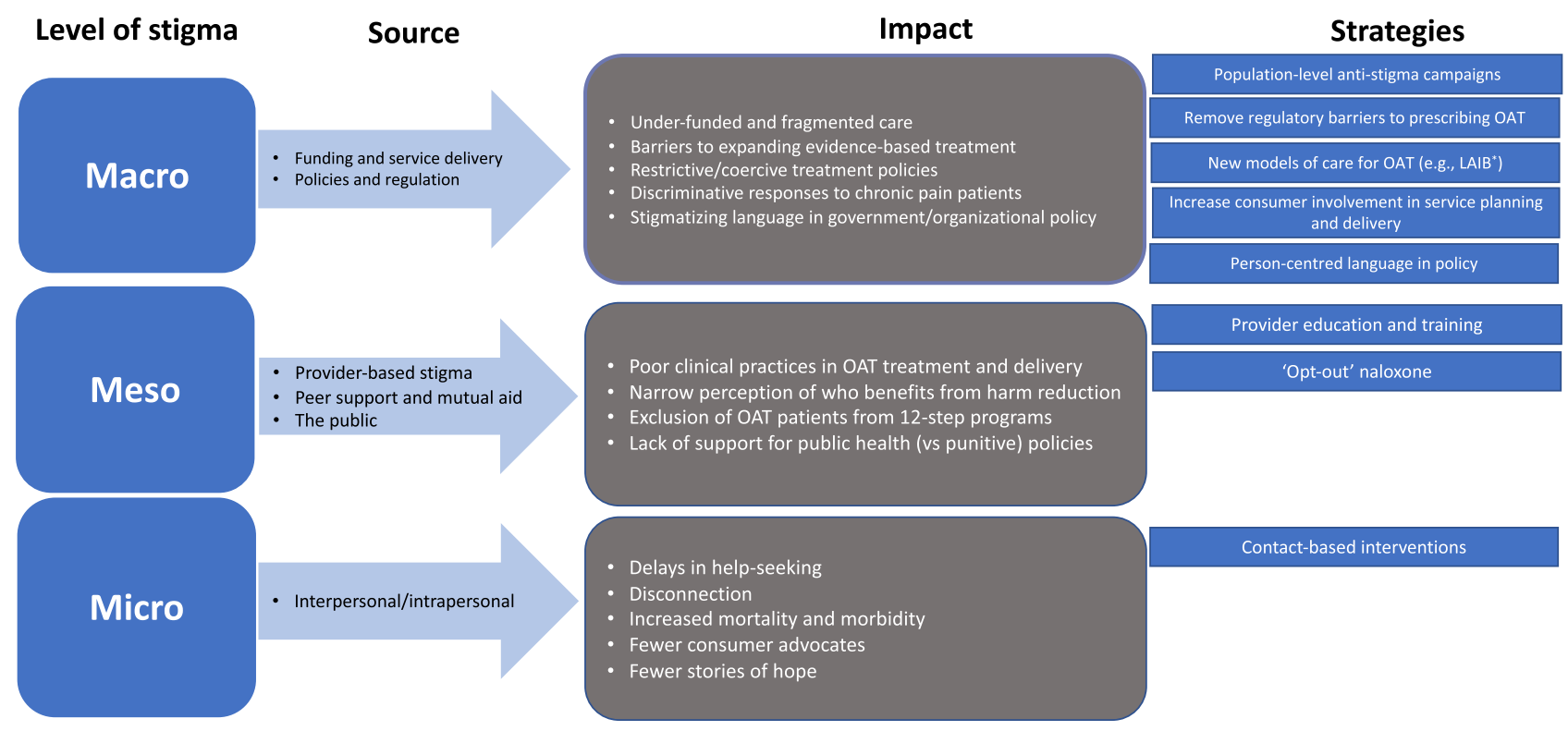

Figure I Levels, source, impact, and strategies to reduce stigma. Note: *Long-acting injectable buprenorphine.

stigma), meso (public stigma) and micro (internalised stigma) levels, with a focus on how these impact opioid use disorder treatment (Figure 1). Following this, we highlight potential strategies and approaches to reduce stigma.

\section{Macro Level}

The underfunding of treatment for opioid use disorder is an important driver of structural stigma, as inequitable allocation of resources means that people face greater barriers to accessing appropriate care for substance use disorders than they do for other health needs. ${ }^{31}$ In addition to exacerbating health inequities, this has the effect of implicitly classifying people seeking treatment as less worthy or undeserving of care. ${ }^{28}$ More broadly, the systemic separation of substance use treatment services from physical and mental health services creates a number of challenges for people with substance use disorders. Institutional policies and funding arrangements that result in a lack of coordination between services reinforce stigma by fragmenting care, while simultaneously producing poorer health outcomes. ${ }^{8,28}$ For example, hospitals are an important component of the continuum of care for opioid use disorder; however, inadequate funding for addiction medicine specialists (who play a key role in referral and linkage to ongoing care) ${ }^{32}$ means structural stigma remains a significant barrier to addressing under-treatment within the acute care system. ${ }^{33}$

Structural stigma is enacted through laws, regulations, and policies that create barriers to accessing evidence-based treatments. ${ }^{31}$ Jurisdiction-based restrictions are often cited as barriers to prescribing opioid agonist therapy (OAT), including methadone and buprenorphine, even though OAT is supported by strong evidence demonstrating its effectiveness in reducing opioid-related harms and mortality. ${ }^{34}$ In certain high-income countries such as Australia, a significant cohort of people access OAT (in 2020 almost 50,000 clients received pharmacotherapies at over 3000 dosing points). ${ }^{35}$ However, in places with high rates of opioid mortality such as the United States (US), the availability of treatment programs including OAT have been slow to expand. ${ }^{36}$ The complex and restrictive regulatory framework surrounding these medications (and in particular, strict regulations governing methadone) is thought to be a key factor underlying the treatment gap in the US. ${ }^{37}$

The stigma associated with OAT is reinforced by restrictive treatment policies that require patients to attend specialised prescribing clinics and comply with strict treatment regimens. For example, OAT programs in Australia typically involve patients being administered daily doses under the supervision of a pharmacist or clinician, with patients eligible to receive "takeaway" doses following a period of treatment stability (eg, low number of missed doses; no evidence of diversion of doses to others). These types of programs have been associated with high levels of stigma, as the 
treatment policies and systems underpinning them frame only certain clients as trustworthy to manage takeaway doses, and patients often have to line up at pharmacies/clinics which potentially publicly identifies them as being treated for opioid use disorder. ${ }^{38-40}$ In addition, although treatment at community pharmacies can normalise provision of care for opioid use disorder, some pharmacies physically separate OAT clients from other customers, which can label them as "other", or even at risk or dangerous. ${ }^{40}$ In particular, strict, long-term methadone programs have been referred to as constricting clients' lifestyles through the "liquid handcuff" metaphor. ${ }^{41}$

Efforts to expand the availability of treatment options are also frequently hampered by regulatory barriers, limited funding, and a lack of governmental and organisational support. This can be seen in the opposition to injectable agonist treatment programs that provide pharmaceutically produced diacetylmorphine or hydromorphone to people who have not responded to first-line treatments. While these programs have been part of standard care in a number of European countries for two decades ${ }^{42}$ and are considered effective treatments for a particularly vulnerable subpopulation, ${ }^{43}$ the first trial of injectable hydromorphone in North America faced significant challenges due largely to the stigma associated with intravenous opioid use. ${ }^{44}$ Specifically, political concerns and a lack of available funding led to all US sites in the trial being abandoned, while misconceptions about the nature and purpose of treatment and fears regarding 'honeypot effects' (ie, drawing people with heroin use disorder from other areas and increasing crime and public disorder) limited recruitment efforts and constrained the implementation of the trial in Canada. ${ }^{44,45}$

Regulatory responses to increasing opioid-related mortality in recent years may have increased stigma towards people who use prescription opioids. Patients with chronic non-cancer pain report experiencing discrimination in health-care settings and increased barriers to treatment since the onset of the opioid epidemic and the implementation of restrictions to limit opioid prescribing. ${ }^{15,46}$ Prescription drug monitoring programs have also been associated with various unintended consequences, with a recent systematic review identifying stigmatising clinical responses (including treatment refusal and discontinuation) in 19 of the 41 studies included. ${ }^{47}$

Stigma can restrict consumer involvement in policy and program development. ${ }^{31}$ Many health services require police checks as a part of employment processes, meaning those who have a criminal history due to their substance use are precluded from participating in service planning and delivery. The credibility of consumers and their capacity to share knowledge can also be undermined when they are viewed with suspicion and disregard, or with limited ability to make decisions as fully rational subjects. ${ }^{8,39,48}$ For example, in a study of experiences and perspectives of staff at a clinic providing heroin-assisted treatment, consumers were blocked from participating due to ethical concerns that they would be "under the influence" and therefore incapable of providing informed consent. ${ }^{48}$ In return, lack of consumer participation can contribute to the design of services that do not take into account structural barriers (eg, restrictive opening hours, fear of police intervention). ${ }^{49}$

Language can reinforce stigma at the macro level, and when written into policies can uphold discriminatory practices and legitimize unfair treatment within the health-care system. ${ }^{50}$ The media, which primarily frames opioid use disorder as a criminal justice issue rather than as a treatable health condition, ${ }^{13}$ is a powerful driver of stigma that reinforces negative stereotypes about people with substance use disorders. ${ }^{51}$ Analysis of US news media over a 15-year period found less than $5 \%$ of stories mentioned expanding substance use treatment (with even fewer mentioning expanding access to medication-assisted treatments), while over 60 discussed law enforcement as a solution to the opioid crisis. ${ }^{13}$

The way the underlying problem and causes of opioid use disorder are constructed within treatment settings can also influence how people experience stigma, care and recovery. The notion that addiction is a medical problem, or a "disease", can be traced back centuries. ${ }^{52}$ Towards the mid-1990s, based on neuroimaging research, a number of prominent US research agencies framed alcohol and other drug addiction as a chronic, relapsing brain disease. ${ }^{53,54}$ The National Institute on Drug Abuse (NIDA) in the US, which funds more than $85 \%$ of global research on drug addiction, ${ }^{55}$ has been a vocal advocate of the brain disease model of addiction since then. Regardless of the accuracy of the neurobiological evidence supporting the brain disease model, ${ }^{56}$ concerns exist regarding its utility in promoting health-based solutions to addiction rather than punitive responses (eg, incarceration), and how it influences stigma experienced by people experiencing opioid use disorder.

Advocates of the brain disease model of addiction argue that it will reduce moral judgments of people with substance use disorders, provide more effective behavioural and medical interventions (eg, anti-craving medication, cognitive brain 
training, and brain stimulation), and foster more effective public health policies for prevention and treatment. ${ }^{53,57}$ However, critics have argued that viewing addiction as a brain disease may increase stigma and lead policymakers to focus on individual medical solutions to social problems. ${ }^{56,58}$ There has been some empirical research examining the association between biogenetic explanations and stigma towards people with substance use disorders. ${ }^{59}$ For instance, although more of the public sampled in the US between 1996 and 2006 embraced a neurobiological understanding of mental illness (including alcohol use disorder), a neurobiological conception was not related to a reduction in stigma towards people with mental illnesses. ${ }^{2}$ Further, some evidence suggests that biomedically oriented explanations of mental illness and addiction may increase perceptions of dangerousness and desire for social distance, as well as pessimism about the likelihood of recovery. ${ }^{60}$

The association between framing opioid use disorder as a disease of the brain and stigma remains critically unresearched given language can shape how the public thinks about treatment and recovery. ${ }^{61}$ There is evidence to suggest that a greater endorsement of disease model beliefs may be associated with more stigmatised attitudes and lesser support for harm reduction initiatives, ${ }^{62}$ however other research suggests that there may not be one single term that is optimal across all settings, with more biomedical terms ("chronically relapsing brain disease") associated with lower levels of stigma and blame, and less medical terminology ("opioid problem") associated with stronger beliefs in recovery. ${ }^{60}$ The terms used to describe opioid use disorder and treatment can influence public support for investment in therapeutic versus punitive responses to opioid use disorder, ${ }^{60,63}$ highlighting the importance of carefully considering how opioid use disorders are framed when presented to the general population, so as to avoid amplifying existing barriers to treatment.

\section{Meso Level}

Organizational norms in the treatment system influence social interactions between providers and patients and can increase prejudice and discrimination. ${ }^{30}$ Negative core beliefs about opioid use disorder and its treatment (eg, "difficult" patients; pessimism about recovery; OAT "replacing one drug for another") may stereotype patients and frame them as manipulative, unmotivated, undeserving of services, and unlikely to achieve lasting recovery. ${ }^{61}$ Stigma from health-care providers can manifest as lower empathy and engagement, non-collaborative and paternalistic approaches, suboptimal or disrupted care, and exclusion from services. ${ }^{29,50,64}$

Research indicates that providers are often reluctant to prescribe OAT due to negative attitudes towards patients, a lack of understanding of opioid use disorder, and pessimism about the effectiveness of treatment. ${ }^{64-66}$ Some report believing that OAT is beyond their scope of practice and does not belong in primary care. ${ }^{65}$ Attitudes among primary care physicians may be more stigmatising than the general public, compounded by fear of attracting "bad" clientele and concerns that providing OAT will have a negative impact on their professional reputation. ${ }^{66}$ Regulatory barriers may have perpetuated negative attitudes and beliefs regarding OAT among prescribers, with the additional training requirements, approval processes, and administrative burden associated with OAT programs signifying that it is onerous and risky. ${ }^{67}$

Compounding these effects, if clients wish to attend mutual aid groups (eg, 12-step programs) in addition to formal care, they often have to conceal their engagement with OAT programs or risk being ostracised for not being "clean" or abstinent. In particular, methadone treatment may be more stigmatised than injecting drug use 5 and perceived as "morally equivalent" to heroin among opioid-using peers and their social network. ${ }^{68}$ Stigma against methadone may be the most pervasive and prevalent type of opioid-related stigma, with broadly comparable beliefs regarding its legitimacy as a medical treatment also documented among prescribers and pharmacists. ${ }^{6}$ Unsurprisingly, in-group stigmatisation of OAT is a strong predictor of discontinuing treatment ${ }^{6}$.

Routine interactions in pharmacy settings have also been identified as a source of stigma and discrimination for OAT patients. Even among samples reporting a high level of satisfaction with treatment, there is evidence that a substantial proportion feel they are treated "differently" to other customers, ${ }^{69}$ and regularly experience subtle verbal and non-verbal negativities directed towards them by pharmacy staff. ${ }^{70}$ In addition, pharmacists may refuse to provide services like syringe sales to people who inject drugs on the basis of appearance, relying on judgements about their moral character rather than an assessment of medical need. ${ }^{5}$ 
Stigma can be a barrier to naloxone supply and expansion of naloxone programs, with the perceptions that the lives of people who use opioids are less valuable and that naloxone has less of a place in mainstream health. ${ }^{71}$ The narrow perception of who may benefit from naloxone supply, and the stigmatised views towards those who use drugs has been shown to be a barrier preventing naloxone supply for pharmacists. ${ }^{72}$ In turn, this means that it has not been available for others at risk populations including people prescribed opioids for pain. ${ }^{73}$ Stigma may also undermine public support for naloxone: where naloxone recipients are perceived as dangerous, there may be less support for programs. ${ }^{74}$

Stigma also has considerable influence on community support of other harm reduction efforts, including safe consumption facilities. For example, only $29 \%$ of US adults support legalizing safe consumption facilities, ${ }^{75}$ and believe they would allow illegal activity and encourage people to use drugs, ${ }^{76}$ with higher levels of stigma associated with lower support. ${ }^{75}$ Consistent with a history of treating drug use as a moral failing and a criminal justice issue rather than a health problem, support for "safe consumption sites" is lower than support for "overdose prevention sites" (with the former emphasising making an illegal activity safer for a highly stigmatised population). ${ }^{77}$ More broadly, stigma towards opioid use is associated with lower support for public health-oriented policies, including passing laws to protect people from criminal charges if they seek help for an overdose and increasing government spending to improve substance use treatment. $^{78}$

\section{Micro Level}

Internalising or anticipating public stigma can have a profound impact on service utilisation and recovery. ${ }^{50}$ In particular, the institutionalised stigma and social control in OAT delivery can reinforce an "addict" identity and lead to treatment becoming a source of shame and disempowerment. ${ }^{40}$ When internalised, the experience of stigma can jeopardise recovery and reintegration with mainstream society, reinforce a low sense of entitlement to quality care, and leave people to leave treatment prematurely. $8,68,79$

The experience of stigma is associated with delays in seeking treatment, increased rates of treatment withdrawal, withholding information in an effort to avoid sub-standard care, as well as increased engagement in risky behaviour such as needle sharing. ${ }^{8}$ Fear of being stigmatised is also a key barrier for carrying naloxone,${ }^{80}$ and can lead to injecting drug users distancing themselves from harm reduction services such as syringe exchanges. ${ }^{5,81}$ Stigma can also result in label avoidance, the process by which people are reluctant to be diagnosed or be seen seeking treatment for an opioid use disorder. As a result, some people (including patients with chronic pain) report reluctance to use opioid medication, and may not identify as having an opioid use disorder or conceal their use of opioid pharmacotherapy to avoid being stigmatised by friends and family. ${ }^{6,82,83}$

\section{Strategies to Reduce Stigma}

Little research exists on the effectiveness of interventions to reduce stigma at the structural or macro level, ${ }^{28}$ particularly in relation to opioid use. However, policy makers and organizational leaders are in a key position to reinforce destigmatising language when describing opioid use disorder and treatment, ${ }^{50,84}$ and evidence suggests that effective communication could increase public support for evidence-based substance use policies and harm reduction initiatives.-

${ }^{78,84}$ Large-scale stigma reduction campaigns also have the potential to alter social and cultural conceptions of opioid use disorder, although these should be carefully considered and built on a robust evidence base to ensure that they do not unintentionally reinforce negative attitudes. ${ }^{2}$ Narratives that humanize the experiences of people with opioid use disorders, emphasise that substance use disorders are treatable, and highlight structural barriers to treatment (eg, inadequate insurance coverage, provider shortages, and lack of availability), may increase public support without leading to a corresponding increase in stigma. ${ }^{84,85}$

Organizations have a major role to play in involving people with lived experience in governance processes, service delivery, evaluation, and care planning. Consumer engagement is a key principle in the planning and delivery of health services, and is increasingly becoming a regulatory requirement in addition to an ethical obligation. ${ }^{86}$ Involving consumers at the systems level is a strategy used worldwide to promote person-centred health-care, and in regard to opioid use may reduce stigmatisation of service users. ${ }^{87}$ Ideally, consumer involvement should also include developing and reviewing policies with the aim of eliminating stigmatising language. ${ }^{60}$ 
Ultimately, reforming laws and policies that create barriers to accessing quality care is critical to address treatment inequities and health disparities among people with opioid use disorder. ${ }^{28,30}$ This includes addressing the institutional policies and systems that fragment care, and integrating substance use disorder treatment into mainstream health-care. Removing regulatory barriers to prescribing OAT, for example, may help normalise treatment within primary care and allow opioid disorder to be managed like other chronic conditions: in addition to improving access, this provides opportunities to manage comorbid mental and physical health problems that may otherwise be left unaddressed ${ }^{88}$ In turn, this may have beneficial effects on stigma enacted at the meso level, as greater exposure to OAT among prescribers is a consistent predictor of more positive attitudes towards treatment. ${ }^{89}$ Similar findings have been reported among pharmacists, and may reflect improvements in knowledge and confidence in addition to a shift in attitudes as they begin witnessing patients' improvements first-hand. ${ }^{89,90}$

Expanding hospital-based models of delivery, such as low-threshold buprenorphine treatment initiated in hospital emergency departments, ${ }^{91}$ may also help normalise OAT and reduce stigma experienced by people with opioid use disorder within these settings. Embedding addiction medicine specialist services in hospitals has been identified as a key strategy to address inadequate or inappropriate treatment during hospitalisation and improve patient outcomes. ${ }^{92}$ Specialists have a key role in building capacity in hospital settings, as well as integrating training and education to address negative attitudes and beliefs regarding hospital-based care for opioid use disorder. ${ }^{93}$ However, structural stigma embedded in funding models positions addiction medicine as of lesser importance than other medical specialities, despite recognition of its essential role in ensuring high-quality care and improved patient outcomes. ${ }^{92}$

Addressing regulatory barriers to providing methadone (particularly in the US, where it is only available via accredited opioid treatment programs), ${ }^{94,95}$ may be beneficial in addressing the considerable stigma associated with this medication. While studies examining clinician attitudes have typically identified general barriers providing OAT (eg, concerns about "difficult" patients) rather than barriers associated with specific medications (eg, sublingual buprenorphine versus naltrexone), ${ }^{96}$ methadone is subject to unique stigma ${ }^{6}$ that may be compounded by its strict regulation. Retaining and expanding regulatory changes implemented during the COVID-19 pandemic to aid continuity of care ${ }^{97,98}$ is increasingly been recognised an important step in developing innovative models of care to address the opioid crisis, ${ }^{98,99}$ and may also reduce the stigma associated with methadone if treatment is made more accessible.

At the same time, there is a clear opportunity to reorient prescriber education and practices to reduce stigma. ${ }^{100}$ This could be achieved by providing comprehensive training during medical school or residency. Structured education that focuses on opioid use disorder treatment and emphasises recovery, as well as programs that include contact with patients in one-on-one or small group settings, has been found to decrease stigma and increase confidence and interest in providing OAT in later practice. ${ }^{101-103}$

Much has been written about the need to address the restrictive and coercive elements of OAT delivery. ${ }^{39,40,68}$ The recent introduction of long-acting injectable depot buprenorphine may offer an alternate approach to how OAT treatment could be delivered. Depot buprenorphine delivers prolonged therapeutic doses of buprenorphine in weekly or monthly formulations, and has been shown to be safe and effective treatment for opioid use disorder. ${ }^{104,105}$ It may also overcome many issues associated with sublingual OAT, such as poor adherence, risk of diversion or non-medical use of takeaway doses. ${ }^{106}$ Recent qualitative research exploring Australian clients' experiences of depot buprenorphine has indicated that depot buprenorphine afforded positive benefits for many participants, including opportunities to avoid stigma experienced at pharmacies/clinics by not having to dose daily. Furthermore, depot buprenorphine allowed clients time to engage in activities (eg, travel, work) by releasing participants from previous OAT treatment regimens which helped them to form a new, non-stigmatised identity and a feeling of "normality". However, for some clients, moving to depot buprenorphine disrupted engagements with important social/practical supports available at pharmacies/clinics. ${ }^{107}$ More broadly, early research has indicated that depot buprenorphine is a viable treatment option in prison settings (with benefits including lower risk of diversion and potentially lowering harms associated with injecting drug use, ie, bloodborne virus risks). ${ }^{108}$ Going forward, how depot buprenorphine is experienced in different international contexts, including how it may reduce stigma experienced in care settings, remains an important area of research.

Specific intervention strategies are needed to address the stigma around naloxone, and barriers to broader naloxone supply for people who use opioids. Illicit substance use is highly stigmatised and enormous efforts are needed in this 
space, yet prescribed opioid use which has its own stigma attached warrants consideration. ${ }^{109}$ One strategy to start to remove barriers to naloxone supply is to use a universal approach to screening and offering naloxone, with "opt-out" methods proposed for naloxone supply (ie, offering naloxone whenever opioids are discussed, without targeting specific populations). ${ }^{110}$ As health-care providers exist within communities, broader population-based efforts to reduce the stigma associated with substance use may reduce barriers to naloxone supply. Indeed, for as long as naloxone provision remains connected to illicit substance use, and the stigma associated with that, it is likely that barriers will remain.

Addressing stigmatising attitudes towards safe consumption facilities has proven to be an ongoing challenge. Despite evidence supporting their effectiveness, stigmatised views of safe consumption facilities and the people that use them are common among key stakeholder groups (eg, police, politicians, local businesses, residents), including the perception that they encourage initiation of injecting drug use, discourage people from seeking treatment, and increase neighbourhood crime. However, research suggests that attitudes may be improved when there is a collaborative approach to implementation (ie, between government, health-care, community, and law enforcement), an emphasis on community consultation and potential local impacts, and when facilities are situated within a comprehensive response to substance use treatment. ${ }^{111,112}$

With regard to stigma at the micro level, there is evidence that contact-based interventions that individualise and humanise people who use drugs may help reduce social distance. ${ }^{100,113}$ Building on the larger evidence base on stigma reduction in relation to mental health and HIV, contact-based interventions involve facilitating direct interaction between people living with stigmatised conditions and medical professionals and/or the general public (eg, through workshop where people with lived experience describe their challenges and personal experiences with stigma and recovery to targeted audiences). ${ }^{114,115}$ Contact-based interventions can also be implemented using digital strategies, as demonstrated by the US-based "Life Unites Us" campaign. ${ }^{116}$ A key component of this is a public campaign featuring video testimonials from people with lived experience of opioid use disorder and their families, presented alongside educational messages addressing key drivers of stigma (eg, the effectiveness of treatment, misconceptions about opioid use disorder, negative stereotypes). Preliminary results point towards high levels of positive engagement among people with lived experience as well as the general public, and suggest the campaign has potential to improve public stigma, as well as reducing self-stigma by empowering those who tell their stories. ${ }^{116}$

However, the social processes that lead to the formation of "ingroups" and "outgroups" are a fundamental part of human interaction and identity formation, and the micro-level stigma that emerges from this is deeply embedded in social and cultural norms. ${ }^{30}$ In turn, these cannot be separated from the broader context in which they operate and the laws, regulations, and rules that segregate people with opioid and other substance use disorders from mainstream society. ${ }^{28}$

\section{Conclusions}

Opioid use disorder remains highly stigmatised, with specific regulations regarding opioid prescribing, treatment delivery structures, and organisational and social norms serving to reinforce stigma in the treatment system and broader society. As it is important to address the numerous disparities that risk isolating people and creating barriers to receiving highquality care, efforts to address this should focus on stigma at multiple levels. However, given the numerous structural sources of opioid-related stigma, strategies that focus on micro or meso-level stigma (eg, personal contact or training) are unlikely to be sufficient if done in isolation. ${ }^{30}$ Rather, change at the level of policy and systems is needed to ensure that people with opioid use disorder are treated with the same dignity and respect as any other patient group.

\section{Funding}

SN, LP and DL are supported by NHMRC Grants (\#1163961, \# 1189975 and \# 1196892). LP is also the recipient of the Monash Addiction Research Centre (MARC) PhD Top Up Scholarship.

\section{Disclosure}

SN has received untied educational research funding from Seqirus, and is a named investigator on a buprenorphine depot implementation study funded by Indivior. DL has previously received speaking honoraria from AstraZeneca, Camurus 
$\mathrm{AB}$, Indivior, Janssen and Lundbeck and has provided consultancy advice to Lundbeck and Indivior. DL and AB have received research funding from Camurus $\mathrm{AB}$. The authors report no other conflicts of interest in this work.

\section{References}

1. Degenhardt L, Grebely J, Stone J, et al. Global patterns of opioid use and dependence: harms to populations, interventions, and future action. Lancet. 2019;394(10208):1560-1579. doi:10.1016/S0140-6736(19)32229-9

2. Pescosolido BA, Martin JK, Long JS, Medina TR, Phelan JC, Link BG. "A disease like any other"? A decade of change in public reactions to schizophrenia, depression, and alcohol dependence. Am J Psychiatry. 2010;167(11):1321-1330. doi:10.1176/appi.ajp.2010.09121743

3. Corrigan PW, Kuwabara SA, O'Shaughnessy J. The public stigma of mental illness and drug addiction: findings from a stratified random sample. J Soc Work. 2009;9(2):139-147. doi:10.1177/1468017308101818

4. Janulis P, Ferrari JR, Fowler P. Understanding public stigma toward substance dependence. J Appl Soc Psychol. 2013;43(5):1065-1072. doi:10.1111/jasp. 12070

5. Paquette CE, Syvertsen JL, Pollini RA. Stigma at every turn: health services experiences among people who inject drugs. Int J Drug Policy. 2018;57:104-110. doi:10.1016/j.drugpo.2018.04.004

6. McCradden MD, Vasileva D, Orchanian-Cheff A, Buchman DZ. Ambiguous identities of drugs and people: a scoping review of opioid-related stigma. Int J Drug Policy. 2019;74:205-215. doi:10.1016/j.drugpo.2019.10.005

7. Brown SA. Stigma towards marijuana users and heroin users. J Psychoactive Drugs. 2015;47(3):213-220. doi:10.1080/02791072.2015.1056891

8. Lloyd C. Sinning and Sinned Against: The Stigmatisation of Problem Drug Users. London: UK Drug Policy Commission; 2010:28.

9. Webster F, Rice K, Sud A. A critical content analysis of media reporting on opioids: the social construction of an epidemic. Soc Sci Med. 2020;244:112642. doi:10.1016/j.socscimed.2019.112642

10. Taxel S. Fentanyl facts and fiction: a safety guide for first responders. J Emerg Med Services. 2019;5(7). https://www.jems.com/operations/ fentanyl-facts-and-fiction-a-safety-guide-for-first-responders/

11. Del Pozo B, Sightes E, Kang S, Goulka J, Ray B, Beletsky LA. Can touch this: training to correct police officer beliefs about overdose from incidental contact with fentanyl. Health Justice. 2021;9(1):1-6. doi:10.1186/s40352-021-00163-5

12. Netherland J, Hansen HB. The war on drugs that wasn't: wasted whiteness, "dirty doctors," and race in media coverage of prescription opioid misuse. Cult Med Psychiatry. 2016;40(4):664-686. doi:10.1007/s11013-016-9496-5

13. McGinty EE, Kennedy-Hendricks A, Baller J, Niederdeppe J, Gollust S, Barry CL. Criminal activity or treatable health condition? News media framing of opioid analgesic abuse in the United States, 1998-2012. Psychiatr Services. 2016;67(4):405-411. doi:10.1176/appi.ps.201500065

14. Perry BL, Pescosolido BA, Krendl AC. The unique nature of public stigma toward non-medical prescription opioid use and dependence: a national study. Addiction. 2020;115(12):2317-2326. doi:10.1111/add.15069

15. Dassieu L, Heino A, Develay É, et al. Conversations about opioids: impact of the opioid overdose epidemic on social interactions for people who live with chronic pain. Qual Health Res. 2021;31:10497323211003063.

16. Antoniou T, Ala-Leppilampi K, Shearer D, Parsons JA, Tadrous M, Gomes T. "Like being put on an ice floe and shoved away": a qualitative study of the impacts of opioid-related policy changes on people who take opioids. Int J Drug Policy. 2019;66:15-22. doi:10.1016/j. drugpo.2019.01.015

17. Kulesza M, Larimer ME, Rao D. Substance use related stigma: what we know and the way forward. J Addict Behav Ther Rehabil. 2013;2 (2):782. doi:10.4172/2324-9005.1000106

18. Newman BN, Crowell KA. The intersectionality of criminality and substance use self-stigmas. Stigma Health. 2021. doi:10.1037/sah0000293

19. El-Bassel N, Shoptaw S. Addressing long overdue social and structural determinants of the opioid epidemic. Elsevier. 2021;222(1):108679.

20. Sander G, Scandurra A, Kamenska A, et al. Overview of harm reduction in prisons in seven European countries. Harm Reduct J. 2016;13(1):113. doi:10.1186/s12954-016-0118-x

21. Komalasari R, Wilson S, Haw S. A systematic review of qualitative evidence on barriers to and facilitators of the implementation of opioid agonist treatment (OAT) programmes in prisons. Int J Drug Policy. 2021;87:102978. doi:10.1016/j.drugpo.2020.102978

22. Conner KO, Rosen D. "You're nothing but a junkie": multiple experiences of stigma in an aging methadone maintenance population. $J$ Soc Work Pract Addict. 2008;8(2):244-264. doi:10.1080/15332560802157065

23. Turan JM, Elafros MA, Logie CH, et al. Challenges and opportunities in examining and addressing intersectional stigma and health. BMC Med. 2019;17(1):1-15. doi:10.1186/s12916-018-1246-9

24. World Health Organization. The World Health Report: 2001: Mental Health: New Understanding, New Hope. World Health Organization; 2001.

25. Goffman E. Stigma: Notes on the Management of Spoiled Identity. Prentice Hall; 1963.

26. Thornicroft G, Rose D, Kassam A, Sartorius N. Stigma: ignorance, prejudice or discrimination? Br J Psychiatr. 2007;190(3):192-193. doi:10.1192/bjp.bp.106.025791

27. Corrigan PW, Larson JE, Rüsch N. Self-stigma and the "why try" effect: impact on life goals and evidence-based practices. World Psychiatr. 2009;8(2):75-81. doi:10.1002/j.2051-5545.2009.tb00218.x

28. Livingston JD. Structural Stigma in Health-Care Contexts for People with Mental Health and Substance Use Issues. Ottowa, Canada: Mental Health Commission of Canada; 2020.

29. Nyblade L, Stockton MA, Giger K, et al. Stigma in health facilities: why it matters and how we can change it. BMC Med. 2019;17(1):25. doi:10.1186/s12916-019-1256-2

30. Pescosolido BA, Martin JK, Lang A, Olafsdottir S. Rethinking theoretical approaches to stigma: a Framework Integrating Normative Influences on Stigma (FINIS). Soc Sci Med. 2008;67(3):431-440. doi:10.1016/j.socscimed.2008.03.018

31. Livingston JD. A Framework for Assessing Structural Stigma in Health-Care Contexts for People with Mental Health and Substance Use Issues. Ottawa, Canada: Mental Health Commission of Canada; 2021.

32. Priest KC, McCarty D. The role of the hospital in the 21 st century opioid overdose epidemic: the addiction medicine consult service. $J$ Addict Med. 2019;13(2):104. doi:10.1097/ADM.0000000000000496 
33. Samuels EA, McDonald JV, McCormick M, Koziol J, Friedman C, Alexander-Scott N. Emergency department and hospital care for opioid use disorder: implementation of statewide standards in Rhode Island, 2017-2018. Am J Public Health. 2019;109(2):263-266. doi:10.2105/ AJPH.2018.304847

34. Mattick RP, Breen C, Kimber J, Davoli M. Buprenorphine maintenance versus placebo or methadone maintenance for opioid dependence. Cochrane Database Syst Rev. 2014;(2). doi:10.1002/14651858.CD002207.pub4

35. AIHW. National Opioid Pharmacotherapy Statistics Annual Data Collection. Vol. Cat. no: PHE 266. Australian Institute of Health and Welfare; 2021.

36. Haffajee RL, Lin LA, Bohnert AS, Goldstick JE. Characteristics of US counties with high opioid overdose mortality and low capacity to deliver medications for opioid use disorder. JAMA Netw Open. 2019;2(6):e196373-e196373. doi:10.1001/jamanetworkopen.2019.6373

37. Weber EM. Failure of physicians to prescribe pharmacotherapies for addiction: regulatory restrictions and physician resistance. $J$ Health Care $L$ Poly. 2010;13:49.

38. Anstice S, Strike CJ, Brands B. Supervised methadone consumption: client issues and stigma. Subst Use Misuse. 2009;44(6):794-808. doi:10.1080/10826080802483936

39. Fraser S, Valentine K. Substance and Substitution: Methadone Subjects in Liberal Societies. Springer; 2008.

40. Harris J, McElrath K. Methadone as social control: institutionalized stigma and the prospect of recovery. Qual Health Res. 2012;22(6):810-824. doi:10.1177/1049732311432718

41. Smith CB. A users' guide to 'Juice Bars' and 'Liquid Handcuffs' fluid negotiations of subjectivity, space and the substance of methadone treatment. Space Culture. 2011;14(3):291-309. doi:10.1177/1206331211412238

42. Strang J, Groshkova T, Metrebian N; European Monitoring Centre for Drugs and Drug Addiction. New Heroin-Assisted Treatment: Recent Evidence and Current Practices of Supervised Injectable Heroin Treatment in Europe and Beyond. Vol. 170. Publications Office of the European Union Luxembourg; 2012.

43. Ferri M, Davoli M, Perucci CA. Heroin maintenance for chronic heroin-dependent individuals. Cochrane Database Syst Rev. 2010;(8). doi10.1002/14651858.CD003410

44. Oviedo-Joekes E, Nosyk B, Marsh DC, et al. Scientific and political challenges in North America's first randomized controlled trial of heroinassisted treatment for severe heroin addiction: rationale and design of the NAOMI Study. Clin Trials. 2009;6(3):261-271. doi:10.1177/ 1740774509105222

45. Gartry CC, Oviedo-Joekes E, Laliberté N, Schechter MT. NAOMI: the trials and tribulations of implementing a heroin assisted treatment study in North America. Harm Reduct J. 2009;6(1):1-14. doi:10.1186/1477-7517-6-2

46. Kaboré J-L, Pagé MG, Martel MO, et al. Impact of the opioid epidemic and associated prescribing restrictions on people who live with chronic noncancer pain in Canada. Clin J Pain. 2021;37(8):607-615. doi:10.1097/AJP.0000000000000951

47. Picco L, Lam T, Haines S, Nielsen S. How prescription drug monitoring programs influence clinical decision-making: a mixed methods systematic review and meta-analysis. Drug Alcohol Depend. 2021;228:109090. doi:10.1016/j.drugalcdep.2021.109090

48. McCall J, Caine V, Phillips JC. The patients have a story to tell: informed consent for people who use illicit opiates in a qualitative research project. Crosstown Clin. 2019;91. doi:10.1177/0969733020901814

49. Suárez AL, Clua-García R. Public policies for people who use drugs: strategies for the elimination of stigma and the promotion of human rights. Salud Colect. 2021;17:e3041. doi:10.18294/sc.2021.3041

50. Knaak SM, Christie R, Stuart H. Stigma and the Opioid Crisis: Final Report. Ottawa, Canada: Mental Health Commission of Canada; 2019.

51. McGinty EE, Stone EM, Kennedy-Hendricks A, Barry CL. Stigmatizing language in news media coverage of the opioid epidemic: implications for public health. Prev Med. 2019;124:110-114. doi:10.1016/j.ypmed.2019.03.018

52. Campbell ND. Discovering Addiction: The Science and Politics of Substance Abuse Research. University of Michigan Press; 2007.

53. Leshner AI. Addiction is a brain disease, and it matters. (Cover story). Article. Science. 1997;278(5335):45-47. doi:10.1126/ science.278.5335.45

54. Volkow ND. Editorial: what do we know about drug addiction? Am J Psychiatry. 2005;162(8):1401-1402. doi:10.1176/appi.ajp.162.8.1401

55. US Government Printing Office. Senate hearing 105-573. Drug addiction and recovery. Available from: https://www.gpo.gov/fdsys/pkg/CHRG105shrg49670/html/CHRG-105shrg49670.htm. Accessed December 20, 2021.

56. Hall W, Carter A, Forlini C. The brain disease model of addiction: is it supported by the evidence and has it delivered on its promises? Lancet Psychiatr. 2015;2(1):105-110. doi:10.1016/S2215-0366(14)00126-6

57. Volkow ND, Koob GF, McLellan AT, Longo DL. Neurobiologic advances from the brain disease model of addiction. N Engl J Med. 2016;374 (4):363-371. doi:10.1056/NEJMra1511480

58. Hammer R, Dingel M, Ostergren J, Partridge B, McCormick J, Koenig BA. Addiction: current criticism of the brain disease paradigm. Article. AJOB Neurosci. 2013;4(3):27-32. doi:10.1080/21507740.2013.796328

59. Kvaale EP, Gottdiener WH, Haslam N. Biogenetic explanations and stigma: a meta-analytic review of associations among laypeople. Soc Sci Med. 2013;96:95-103. doi:10.1016/j.socscimed.2013.07.017

60. Kelly JF, Greene MC, Abry A. A US national randomized study to guide how best to reduce stigma when describing drug-related impairment in practice and policy. Addiction. 2021;116(7):1757-1767. doi:10.1111/add.15333

61. Broyles LM, Binswanger IA, Jenkins JA, et al. Confronting Inadvertent Stigma and Pejorative Language in Addiction Scholarship: A Recognition and Response. Taylor \& Francis; 2014.

62. Wild TC, Koziel J, Anderson-Baron J, et al. Public support for harm reduction: a population survey of Canadian adults. PLoS One. 2021;16(5): e0251860. doi:10.1371/journal.pone.0251860

63. Kennedy-Hendricks A, Barry CL, Gollust SE, Ensminger ME, Chisolm MS, McGinty EE. Social stigma toward persons with prescription opioid use disorder: associations with public support for punitive and public health-oriented policies. Psychiatr Services. 2017;68(5):462-469. doi:10.1176/appi.ps.201600056

64. Stone EM, Kennedy-Hendricks A, Barry CL, Bachhuber MA, McGinty EE. The role of stigma in US primary care physicians' treatment of opioid use disorder. Drug Alcohol Depend. 2021;221:108627. doi:10.1016/j.drugalcdep.2021.108627

65. Louie DL, Assefa MT, McGovern MP. Attitudes of primary care physicians toward prescribing buprenorphine: a narrative review. BMC Fam Pract. 2019;20(1):1-8. doi:10.1186/s12875-019-1047-z 
66. Kennedy-Hendricks A, Busch SH, McGinty EE, et al. Primary care physicians' perspectives on the prescription opioid epidemic. Drug Alcohol Depend. 2016;165:61-70. doi:10.1016/j.drugalcdep.2016.05.010

67. Prathivadi P, Sturgiss EA. When will opioid agonist therapy become a normal part of comprehensive health care? Med J Aust. 2021;214 (11):504-505. e1. doi:10.5694/mja2.51095

68. Radcliffe P, Stevens A. Are drug treatment services only for 'thieving junkie scumbags'? Drug users and the management of stigmatised identities. Soc Sci Med. 2008;67(7):1065-1073. doi:10.1016/j.socscimed.2008.06.004

69. Lea T, Sheridan J, Winstock A. Consumer satisfaction with opioid treatment services at community pharmacies in Australia. Pharm World Sci. 2008;30(6):940-946. doi:10.1007/s11096-008-9257-9

70. Patil Vishwanath T, Cash P, Cant R, Mummery J, Penney W. The lived experience of Australian opioid replacement therapy recipients in a community-based program in regional Victoria. Drug Alcohol Rev. 2019;38(6):656-663. doi:10.1111/dar.12979

71. Fomiatti R, Farrugia A, Fraser S, Dwyer R, Neale J, Strang J. Addiction stigma and the production of impediments to take-home naloxone uptake. Health. 2020;1363459320925863. doi:10.1177/1363459320925863

72. Olsen A, Lawton B, Dwyer R, et al. Why aren't Australian pharmacists supplying naloxone? Findings from a qualitative study. Int $J$ Drug Policy. 2019;69:46-52. doi:10.1016/j.drugpo.2019.03.020

73. Nielsen S, Olsen A. Using the behaviour change wheel to understand and address barriers to pharmacy naloxone supply in Australia. Int J Drug Policy. 2021;90:103061. doi:10.1016/j.drugpo.2020.103061

74. Ledford V, Lim JR, Namkoong K, Chen J, Qin Y. The influence of stigmatizing messages on danger appraisal: examining the model of stigma communication for opioid-related stigma, policy support, and related outcomes. Health Commun. 2021;1-13. doi:10.1080/ 10410236.2021.1920710

75. McGinty EE, Barry CL, Stone EM, et al. Public support for safe consumption sites and syringe services programs to combat the opioid epidemic. Prev Med. 2018;111:73-77. doi:10.1016/j.ypmed.2018.02.026

76. Barry CL, Sherman SG, Stone E, et al. Arguments supporting and opposing legalization of safe consumption sites in the US. Int J Drug Policy. 2019;63:18-22. doi:10.1016/j.drugpo.2018.10.008

77. Barry CL, Sherman SG, McGinty EE. Language matters in combatting the opioid epidemic: safe consumption sites versus overdose prevention sites. Am Public Health Assoc. 2018;108(9):1157-1159. doi:10.2105/AJPH.2018.304588

78. Bachhuber MA, McGinty EE, Kennedy-Hendricks A, Niederdeppe J, Barry CL. Messaging to increase public support for naloxone distribution policies in the United States: results from a randomized survey experiment. PLoS One. 2015;10(7):e0130050. doi:10.1371/journal. pone. 0130050

79. Farrugia A, Pienaar K, Fraser S, Edwards M, Madden A. Basic care as exceptional care: addiction stigma and consumer accounts of quality healthcare in Australia. Health Sociol Rev. 2020;1-16. doi:10.1080/14461242.2020.1850317

80. Bennett AS, Freeman R, Des Jarlais DC, Aronson ID. Reasons people who use opioids do not accept or carry no-cost naloxone: qualitative interview study. JMIR Form Res. 2020;4(12):e22411-e22411. doi:10.2196/22411

81. Gunn A, Guarino H. "Not human, dead already": perceptions and experiences of drug-related stigma among opioid-using young adults from the former Soviet Union living in the US. Int J Drug Policy. 2016;38:63-72. doi:10.1016/j.drugpo.2016.10.012

82. Nielsen S, Lintzeris N, Murnion B, et al. Understanding an emerging treatment population: protocol for and baseline characteristics of a prospective cohort of people receiving treatment for pharmaceutical opioid dependence. Drug Alcohol Rev. 2018;37(7):887-896. doi:10.1111/ dar. 12859

83. Cooper S, Nielsen S. Stigma and social support in pharmaceutical opioid treatment populations: a scoping review. Int $J$ Ment Health Addict. 2017;15(2):452-469. doi:10.1007/s11469-016-9719-6

84. McGinty E, Pescosolido B, Kennedy-Hendricks A, Barry CL. Communication strategies to counter stigma and improve mental illness and substance use disorder policy. Psychiatr Services. 2018;69(2):136-146. doi:10.1176/appi.ps.201700076

85. McGinty EE, Goldman HH, Pescosolido B, Barry CL. Portraying mental illness and drug addiction as treatable health conditions: effects of a randomized experiment on stigma and discrimination. Soc Sci Med. 2015;126:73-85. doi:10.1016/j.socscimed.2014.12.010

86. DeCamp M, Brewer SE, Dukhanin V. Patient, public, consumer, and community engagement: from consucrat to representative; comment on "the rise of the consucrat". Int J Health Policy Manag. 2021;10(8):503-506.

87. Patterson S, Weaver T, Agath K, et al. 'They can't solve the problem without us': a qualitative study of stakeholder perspectives on user involvement in drug treatment services in England. Health Soc Care Community. 2009;17(1):54-62. doi:10.1111/j.1365-2524.2008.00797.x

88. Saloner B, Stoller KB, Alexander GC. Moving addiction care to the mainstream-improving the quality of buprenorphine treatment. $N$ Engl $J$ Med. 2018;379(1):4-6. doi:10.1056/NEJMp1804059

89. Brown AR. Health professionals' attitudes toward medications for opioid use disorder. Substance Abuse. 2021;1-17. doi:10.1080/ 08897077.2021.1975872

90. Raisch DW, Fudala PJ, Saxon AJ, et al. Pharmacists' and technicians' perceptions and attitudes toward dispensing buprenorphine/naloxone to patients with opioid dependence. J Am Pharm Assoc. 2005;45(1):23-32. doi:10.1331/1544345052843200

91. Fox L, Nelson LS. Emergency department initiation of buprenorphine for opioid use disorder: current status, and future potential. CNS Drugs. 2019;33(12):1147-1154. doi:10.1007/s40263-019-00667-7

92. Nielsen S, Lubman DI. Time to address addiction treatment inequality in hospital settings. Lancet Public Health. 2021;7:e6-e7. doi:10.1016/ S2468-2667(21)00260-7

93. Calcaterra SL, Binswanger IA, Edelman EJ, McNair BK, Wakeman SE, O'Connor PG. The impact of access to addiction specialist on attitudes, beliefs and hospital-based opioid use disorder related care: a survey of hospitalist physicians. Substance Abuse. 2020;1-9. doi:10.1080/ 08897077.2020.1748169

94. Calcaterra S, Bach P, Chadi A, et al. Methadone matters: what the United States can learn from the global effort to treat opioid addiction. $J$ Gen Intern Med. 2019;34(6):1039-1042. doi:10.1007/s11606-018-4801-3

95. Bach P, Hartung D. Leveraging the role of community pharmacists in the prevention, surveillance, and treatment of opioid use disorders. Addict Sci Clin Pract. 2019;14(1):1-11. doi:10.1186/s13722-019-0158-0

96. Andraka-Christou B, Capone MJ. A qualitative study comparing physician-reported barriers to treating addiction using buprenorphine and extended-release naltrexone in US office-based practices. Int J Drug Policy. 2018;54:9-17. doi:10.1016/j.drugpo.2017.11.021 
97. Li R, Zhao M. Maintaining treatment and prevention programs for opioid use disorders during the coronavirus disease 2019 pandemic. Curr Opin Psychiatry. 2021;34(4):369. doi:10.1097/YCO.0000000000000708

98. Peckham AM, Ball J, Colvard MD, et al. Leveraging pharmacists to maintain and extend buprenorphine supply for opioid use disorder amid COVID-19 pandemic. Am J Health Syst Pharm. 2021;78(7):613-618. doi:10.1093/ajhp/zxab003

99. Lynch M, O'Leary AC. COVID-19 related regulatory change for pharmacists-The case for its retention post the pandemic. Res Soc Administr Pharm. 2021;17(1):1913-1919. doi:10.1016/j.sapharm.2020.07.037

100. Livingston JD, Milne T, Fang ML, Amari E. The effectiveness of interventions for reducing stigma related to substance use disorders: a systematic review. Addiction. 2012;107(1):39-50. doi:10.1111/j.1360-0443.2011.03601.x

101. Silins E, Conigrave KM, Rakvin C, Dobbins T, Curry K. The influence of structured education and clinical experience on the attitudes of medical students towards substance misusers. Drug Alcohol Rev. 2007;26(2):191-200. doi:10.1080/09595230601184661

102. Suzuki J, Connery HS, Ellison TV, Renner JA. Preliminary survey of office-based opioid treatment practices and attitudes among psychiatrists never receiving buprenorphine training to those who received training during residency. Am J Addict. 2014;23(6):618-622. doi:10.1111/j.15210391.2014.12143.x

103. Ayu AP, van der Ven M, Suryani E, et al. Improving medical students' attitude toward patients with substance use problems through addiction medicine education. Substance Abuse. 2020;1-9. doi:10.1080/08897077.2020.1732512

104. Haight BR, Learned SM, Laffont CM, et al. Efficacy and safety of a monthly buprenorphine depot injection for opioid use disorder: a multicentre, randomised, double-blind, placebo-controlled, phase 3 trial. Lancet. 2019;393(10173):778-790. doi:10.1016/S0140-6736(18) 32259-1

105. Lofwall MR, Walsh SL, Nunes EV, et al. Weekly and monthly subcutaneous buprenorphine depot formulations vs daily sublingual buprenorphine with naloxone for treatment of opioid use disorder: a randomized clinical trial. JAMA Intern Med. 2018;178(6):764-773. doi:10.1001/ jamainternmed.2018.1052

106. Yokell M, Zaller N, Green T, Rich J. Buprenorphine and buprenorphine/naloxone diversion, misuse, and illicit use: an international review. Curr Drug Abuse Rev. 2011;4(1):28-41. doi:10.2174/1874473711104010028

107. Barnett A, Savic M, Lintzeris N, et al. Tracing the affordances of long-acting injectable depot buprenorphine: a qualitative study of patients' experiences in Australia. Drug Alcohol Depend. 2021;227:108959. doi:10.1016/j.drugalcdep.2021.108959

108. Dunlop AJ, White B, Roberts J, et al. Treatment of opioid dependence with depot buprenorphine (CAM2038) in custodial settings is safe, effective and cost-effective. Addiction. 2018. doi:10.1111/add.15627.

109. Ko J, Chan E, Doroudgar S. Patient perspectives of barriers to naloxone obtainment and use in a primary care, underserved setting: a qualitative study. Substance Abuse. 2021;1-10. doi:10.1080/08897077.2021.1915915

110. Green TC, Case P, Fiske H, et al. Perpetuating stigma or reducing risk? Perspectives from naloxone consumers and pharmacists on pharmacybased naloxone in 2 states. $J$ Am Pharm Assoc (2003). 2017;57(2s):S19-S27.e4.d. doi:10.1016/j.japh.2017.01.013

111. Strike C, Watson TM, Kolla G, Penn R, Bayoumi AM. Ambivalence about supervised injection facilities among community stakeholders. Harm Reduct J. 2015;12(1):1-5. doi:10.1186/s12954-015-0060-3

112. Dupree T, Wood CI, Brace AM. Understanding the stigma and feasibility of opening a safe injection facility in Baltimore City: a qualitative case study. Qual Rep. 2021;26(6):1911-1931.

113. Lloyd C. The stigmatization of problem drug users: a narrative literature review. Drugs Educ Prev Policy. 2013;20(2):85-95.

114. Corrigan PW, Shapiro JR. Measuring the impact of programs that challenge the public stigma of mental illness. Clin Psychol Rev. 2010;30 (8):907-922. doi:10.1016/j.cpr.2010.06.004

115. National Academies of Sciences, Engineering and Medicine. Ending Discrimination Against People with Mental and Substance Use Disorders: The Evidence for Stigma Change. National Academies Press; 2016.

116. Bonneviea E, Kaynakb Ö, Whippleb CR, et al. The life unites us campaign: a novel approach to addressing stigma against opioid use disorder; 2021. Preprint. Available from: https://advance.sagepub.com/articles/preprint/The_Life_Unites_Us_Campaign_A_Novel_Approach_to_ Addressing_Stigma_against_Opioid_Use_Disorder_pdf/14390504. Accessed December 20, 2021.

\section{Publish your work in this journal}

Substance Abuse and Rehabilitation is an international, peer-reviewed, open access journal publishing original research, case reports, editorials, reviews and commentaries on all areas of addiction and substance abuse and options for treatment and rehabilitation. The manuscript management system is completely online and includes a very quick and fair peer-review system. Visit http://www.dovepress.com/testimonials.php to read real quotes from published authors.

Submit your manuscript here: http://www.dovepress.com/substance-abuse-and-rehabilitation-journal 